\title{
Optimization of bio-surfactant production by Azo-rhizobium strain isolated from oil- contaminated soil
}

\author{
Pendse Anuradha, Mhatre Rasika and Aruna K. * \\ Department of Microbiology, Wilson College, Mumbai 400007, Maharashtra, India
}

Publication history: Received on 21 May 2018; accepted on 13 June 2018

Article DOI: https://doi.org/10.30574/gscbps.2018.3.3.0040

\begin{abstract}
Bio-surfactants are amphiphilic molecules possessing both hydrophilic and hydrophobic moieties. They are surface active agents that are produced extracellularly or as a part of the cell membrane by bacteria, yeast, and fungi. In the present study, the screening and optimization of bio-surfactant production were carried out using oil-contaminated soil sample. The cultural, morphological and biochemical tests as well as 16s rRNA analysis identified the most efficient biosurfactant producer as Azorhizobium strain. The preliminary screening of bio-surfactant production was done with the help of oil displacement test, drop collapse test and observed hemolysis on superimposed blood agar plates. Optimization studies revealed that $2 \%$ inoculum size of test strain (1.0 0.D $530 \mathrm{~nm}$ ) can be exploited for bio-surfactant production using $2 \%$ coconut oil and ammonium nitrate with a C: N ratio of 20:1 in MSM medium (pH 8.5) and incubation conditions of $30{ }^{\circ} \mathrm{C}$ for $96 \mathrm{~h}$. The crude yield of bio-surfactant produced was estimated as $2.5 \mathrm{~g} / \mathrm{L}$. Further purification of crude bio-surfactant was carried out using acid hydrolysis and rotary vacuum evaporator. The biosurfactant thus obtained successfully reduced the surface tension of the medium from $59 \mathrm{mN} / \mathrm{m}$ to $38 \mathrm{mN} / \mathrm{m}$ with $\mathrm{E}_{24}$ $60 \%$. The characterization studies of the purified bio-surfactant carried out by FTIR analysis confirmed it to be lipopolysaccharide type of bio-surfactant. Thus our current study suggests useful application of bio-surfactant producing bacterial strain that may be helpful in the petroleum industry for the purpose of recovery of petroleum and other oils from oily sludge, cleaning of oil storage tanks and bioremediation of oil-contaminated sites.
\end{abstract}

Keywords: Bio-surfactant; Optimization; FTIR; Azorhizobium

\section{Introduction}

Polycyclic aromatic hydrocarbons (PAHs) are common environmental contaminants that result primarily from the incomplete combustion of organic matter associated with coal and crude oil processing. Many PAHs and other petroleum hydrocarbons are toxic, mutagenic and carcinogenic in nature [1], and hence pose serious health concerns for humans as well as the environment. One of the main approaches for eliminating these pollutants from contaminated sites involves the process of bioremediation using microorganisms [2].

Bio-surfactants are surface active agents produced by microorganisms when grown on water immiscible or oily substrates [3]. Many microbes degrade natural hydrocarbons viz., saturated and unsaturated alkanes, monoaromatic compounds and low-molecular-mass PAHs to produce bio-surfactants either as cell surface components or extracellular molecules $[4,5]$. However, the biodegradation process of complex PAHs is more demanding due to its hydrophobic nature and the ability to adsorb strongly to soil particles, which results in their limited bioavailability [6]. In order to overcome this problem, recent research focuses on microbial strategies of bio-surfactant production. Presently, a structurally diverse group of surface-active bio-molecules are known. Rhamnolipids from Pseudomonas aeruginosa,

\footnotetext{
${ }^{*}$ Corresponding author

E-mail address: arunasam2000@ yahoo.co.in
}

Copyright (C) 2018 Author(s) retain the copyright of this article. This article is published under the terms of the Creative Commons Attribution Liscense 4.0. 
surfactin from Bacillus subtilis, emulsan from Acinetobacter calcoaceticus and sophorolipids from Candida bombicola are some examples of microbial-derived surfactants [2, 7-9].

Surfactants can accumulate between fluid phases such as oil/water or air/water due to the presence of both hydrophobic (non-polar) and hydrophilic (polar) moieties in their structures. This reduces the surface and interfacial tensions forming emulsions [10]. Hence they are identified as one of the most versatile classes of chemical compounds.

The microbial-derived surfactants have gained popularity since the late 1960s as an improved alternative to chemical surfactants primarily because of their specific action, low toxicity, higher biodegradability, and effectiveness at extremes of temperature, $\mathrm{pH}$, and salinity. In addition, their unique structures provide new properties that classical surfactants may lack. Hence they offer a variety of applications in enhanced oil recovery, medicinal field, food and cosmetic industries $[2,11]$.

In spite of the benefits offered by bio-surfactants, currently, they are outweighed by the disadvantages faced with its applications. One of the major set-backs regarding the use of bio-surfactants is the requirement of raw material (i.e., crude oil) in large quantities for its production. Moreover, the productivity is very low and there occurs intense foaming during the bio-surfactant production [12]. This makes the process expensive and labor extensive. However, the impediment to research progress in the field of bio-surfactant production may be overcome by utilization of waste substrates as raw material to reduce the cost of the process. The development of oxygenation strategies may be applied to reduce the formation of foam [13]. Finally and most importantly, the optimization studies w.r.t growth conditions for production of bio-surfactants may be subjected to genetic modifications, use of combined omics analysis and computational modeling [14]. These efforts will allow the bio-surfactants to be used in large quantities and as preferred replacements for synthetic surfactants in several industrial processes $[13,15]$. Successful application of bio-surfactant producers in oil-contaminated sites may also help in overcoming problems associated with bioremediation $[1,5,16$ 17].

The interest shown by industrialists and scientists in the field of bio-surfactant production can be substantiated with the fact that, in spite of the high cost (3-10 times) of bio-surfactants as compared to chemical surfactant, its production in the global market is expected to reach $4.7 \times 10^{5}$ tons, which is worth 2.2 billion USD, in 2018 from an initial worth of 1.7 billion USD in 2011 [18].

The current study was carried out with an aim to optimize bio-surfactant production from Azorhizobium species and characterize the same in order to obtain high yields.

\section{Material and methods}

\subsection{Enrichment and isolation of bio-surfactant producers}

In our study, the contaminated soil samples were obtained from oil mills and enriched for isolation of bio-surfactant producers. The enrichment was carried out by inoculating $1 \mathrm{~g}$ of the soil sample in $100 \mathrm{ml}$ Nutrient Broth (NB) containing $2 \%$ coconut oil as an inducer and incubating it at $30^{\circ} \mathrm{C}$ for $4-5$ days under shaker $(150 \mathrm{rpm})$ conditions. Isolation of bio-surfactant producers from the enriched medium was carried out on Nutrient Agar (NA) plates incorporated with the inducer and incubated for $4-5$ days at $30^{\circ} \mathrm{C}$.

\subsection{Primary screening of bio-surfactant producers}

Screening for bio-surfactant production was carried out by qualitative methods viz., Oil displacement test, Blood hemolysis test and Drop collapse test using the supernatant obtained by centrifuging pre-grown culture (in NB for $48 \mathrm{~h}$ at $30^{\circ} \mathrm{C}$ ) medium at $8000 \mathrm{rpm}$ for $20 \mathrm{~min}$.

In oil displacement test, $15 \mu \mathrm{l}$ of crude oil was added on the surface of $40 \mu \mathrm{l}$ of distilled water in a petri-dish to form a thin oil layer. To this layer, $10 \mu \mathrm{l}$ of culture supernatant was gently placed at the center. The surfactant activity which correlates to the diameter of the clearing zone on the oil surface was visualized under visible light and recorded after $30 \sec [19]$.

The hemolytic activities of the strains were tested by plating it onto Superimposed Blood Agar (SIBA) and incubating it at $37^{\circ} \mathrm{C}$ for $24-48 \mathrm{~h} \mathrm{[20].} \mathrm{Hemolysis} \mathrm{was} \mathrm{observed} \mathrm{as} \mathrm{a} \mathrm{zone} \mathrm{of} \mathrm{clearance} \mathrm{around} \mathrm{isolated} \mathrm{colonies} \mathrm{after} \mathrm{incubation.}$ 
Pendse et al. / GSC Biological and Pharmaceutical Sciences 2018, 03(03), 035-046

Drop-collapse test was performed in a micro-titer well plate. In this method, $20 \mu \mathrm{l}$ of culture supernatant was added to $7 \mu \mathrm{lmineral}$ oil that was left in the micro-titer well for $24 \mathrm{~h}$ at $30^{\circ} \mathrm{C}$ and the extent of collapse in the drops was examined visually after $1 \mathrm{~min}[21]$.

\subsection{Identification of the bio-surfactant producing organism}

Preliminary identification of the bio-surfactant producers was carried out on the basis of morphological, cultural and biochemical tests in our laboratory, as described in the Bergey's Manual of Determinative Bacteriology, $8^{\text {th }}$ edition [22]. Molecular confirmation of the strain was done by 16s rRNA sequence analysis, which was carried out at Yaazh Xenomics Navi, Mumbai, India.

\subsection{Screening of media for the bio-surfactant production}

Three different media were used for screening of bio-surfactants in our study. The media and its components (in g/L) are listed below.

1. *MSM medium [Glucose (20); Na2HPO4 (2.2); KH2PO4 (1.4); MgSO4.7H2O (0.6); FeSO4. 7 H2O (0.01); NaCl (0.05); $\mathrm{CaCl} 2$ (0.02); Yeast extract (0.02); KI (0.66); ZnSO4. 7H2O (2.32); MnSO4.4H2O (1.78); CuSO4.5H2O (1.0); CoCl2.6H2O (0.42); H3BO3 (0.56); Na2MoO4 (0.39); EDTA (1.0)] [23].

2. *SM medium [Glucose (20); NH4NO3 (3.3); K2HPO4 (2.2); KH2PO4 (0.14); MgSO4.7H2O (0.6); FeSO4. 7 H2O (0.2); $\mathrm{NaCl}$ (0.01); CaCl2 (0.04); Yeast extract (0.1); KI (0.66); ZnSO4. 7H2O (2.32); MnSO4.4H2O (1.78); CuSO4.5H2O (1.0); $\mathrm{CoCl2.6H2O} \mathrm{(0.42);} \mathrm{H3BO3} \mathrm{(0.56);} \mathrm{Na2MoO4} \mathrm{(0.39);} \mathrm{EDTA} \mathrm{(1.0)]} \mathrm{[23].}$

3. Kay's medium $\left[\mathrm{NH}_{4} \mathrm{H}_{2} \mathrm{PO}_{4}\right.$ (2.2); $\mathrm{K}_{2} \mathrm{HPO}_{4}$ (1.4); $\mathrm{MgSO}_{4} .7 \mathrm{H}_{2} \mathrm{O}$ (0.6); $\mathrm{FeSO}_{4} .7 \mathrm{H}_{2} \mathrm{O}$ (0.01); $\mathrm{NaCl}(0.05) ; \mathrm{CaCl} 2$ (0.02); Yeast extract (0.02)] [24].

*The MSM and SM medium used in our study have the same composition with a slight change in concentration of individual components.

The screening and selection of the optimum medium for maximum bio-surfactant production were done on the basis of microbial growth, and maximum surface tension reduction observed.

\subsection{Optimization of culture condition for maximum bio-surfactant production}

The media optimization was conducted in a series of experiments changing one variable at a time, keeping the other factors fixed at a specific set of conditions. These varying factors included $\mathrm{pH}(6.5,7.0,7.5,8.0,8.5,9.0,9.5$ and 10.0), temperatures $\left(30^{\circ} \mathrm{C}, 37^{\circ} \mathrm{C}, 40^{\circ} \mathrm{C}\right.$ and $\left.55^{\circ} \mathrm{C}\right)$, incubation period $(24,48,72,96,120$, and $144 \mathrm{~h}), \mathrm{NaCl}$ concentrations (0.5\%-3\%), carbon sources used as an inducer (Glucose, Glycerol, Sunflower oil, Coconut oil, Palm oil, Soyabean oil) and nitrogen sources (Peptone, Yeast extract, Urea, Ammonium chloride, Ammonium nitrate, Sodium nitrate). In addition, the optimization of C:N ratio was carried out $(10: 1,15: 1,20: 1,25: 1,30: 1,35: 1$ and 40:1) with coconut oil and Ammonium nitrate (i.e., optimized carbon and nitrogen sources) for achieving maximum bio-surfactant production [21, $25,26]$. All the fermentations were carried out in $250 \mathrm{ml}$ Erlenmeyer flasks with $50 \mathrm{ml}$ media and $2 \% \mathrm{v} / \mathrm{v}$ inoculum adjusted to $1.0 \mathrm{O}$ O.D at $530 \mathrm{~nm}$ and all incubations were carried out under shaker $(150 \mathrm{rpm})$ condition. The enriched broth obtained by growing the isolate under test conditions were subjected to centrifugation at $8000 \mathrm{rpm}$ for $20 \mathrm{~min}$ and the cell-free supernatant was tested for surface tension reducing ability and emulsification activity as indicated below.

\subsubsection{Surface tension reduction}

The surface tension of the aqueous solution was measured by using Du Nouy ring-type tensiometer and was carried out after dipping the platinum ring in a solution for a while in order to attain equilibrium conditions. The measurement was repeated three times and an average value was obtained. For calibration of the instrument, the surface tension of the double distilled water was measured, before each set of experiments, which lies between $70 \mathrm{mN} / \mathrm{m}$ to $72 \mathrm{mN} / \mathrm{m}$ [23].

\subsubsection{Activity characterization by determining emulsification index}

The ability of the bio-surfactant to emulsify some liquid hydrocarbons as substrates, such as diesel oil, kerosene, and sunflower oil was determined. The crude bio-surfactant dissolved in $2 \mathrm{ml}$ distilled water was added to each test tube containing the substrate $(2 \mathrm{ml})$. The content of the tubes was vortexed at high speed for $2 \mathrm{~min}$ and left undisturbed for $24 \mathrm{~h}$. The emulsion index (E24) was determined by using the formula 


$$
\text { Emulsion index }=\frac{a}{b} \times 1000
$$

Where "a" is the total height of the emulsion layer and " $b$ " is the total height of the liquid layer [23].

\subsection{Extraction of the bio-surfactant}

For extraction of bio-surfactant from the test isolate, it was first allowed to grow in $100 \mathrm{ml}$ MSM (pH 8.5) for 4 days at $30{ }^{\circ} \mathrm{C}$. The cell-free supernatant obtained by centrifugation of the medium at 8,000 rpm for 20 min was adjusted to pH 2.0 using $6 \mathrm{~N} \mathrm{HCl}$ and kept at $4{ }^{\circ} \mathrm{C}$ overnight in order to precipitate the bio-surfactant. The precipitate was recovered by centrifugation at 10,000 rpm for $20 \mathrm{~min}$. This crude bio-surfactant was dried and further purified by dissolving it in distilled water ( $\mathrm{pH} 7$ ). The bio-surfactant thus obtained was dried at $60{ }^{\circ} \mathrm{C}$ and extracted with Chloroform: Methanol (1:2) solution; filtered and concentrated using a rotary vacuum evaporator [27].

\subsection{Characterization of bio-surfactant by Fourier transform infrared spectroscopy}

The characterization of bio-surfactant obtained in our study was carried out by Fourier transform infrared spectroscopy (FTIR) analysis using Agilent technology Cary 630 instrument. The Spectral scan was normally acquired over the range of $400-4000 \mathrm{~cm}^{-1}[28]$.

\subsection{Statistical analysis}

The experimental data are represented in terms of the arithmetic average of at least three replicates, and the standard deviations are indicated by error bars. The data analysis was done using Microsoft Excel 2007.

\section{Results}

\subsection{Isolation, primary screening, and identification of bio-surfactant producers}

Amongst the six isolates obtained from the enriched medium, isolate 3 appeared to be the most efficient bio-surfactant producer as observed in Table 1. It was identified as Azorhizobium strain on the basis of morphological cultural, biochemical and 16s rRNA analysis.

Table 1 Qualitative screening of Bio-surfactant producers

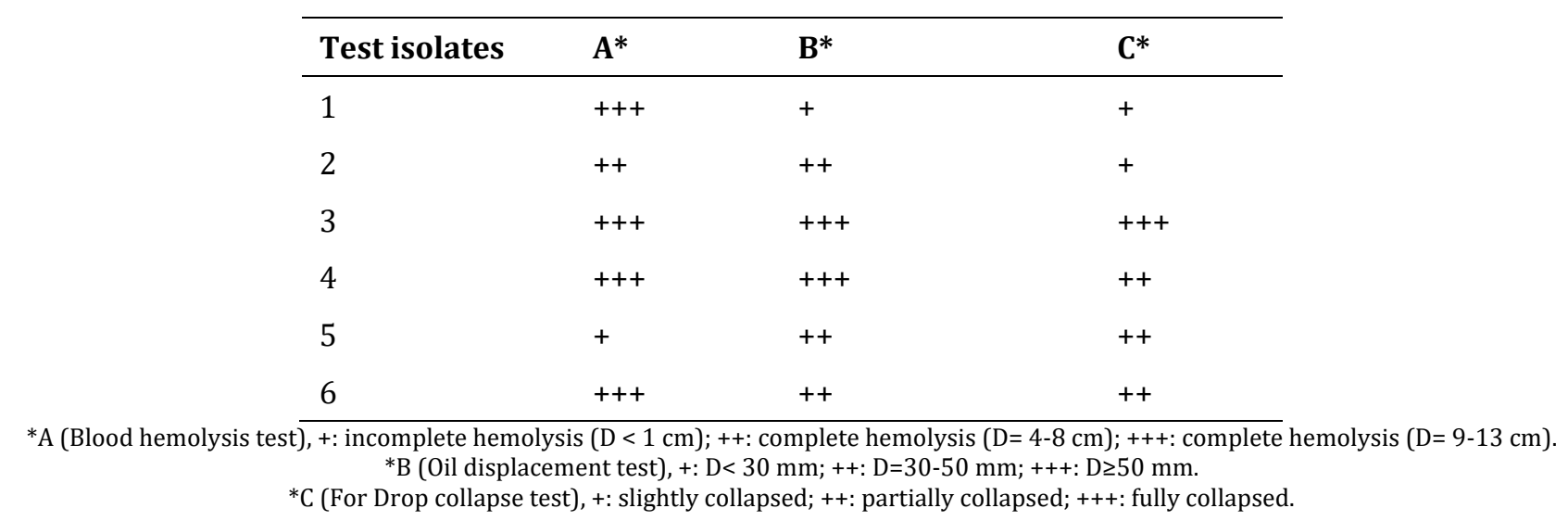

While screening the most efficient bio-surfactant producer, it is necessary to consider more than one qualitative test, keeping in mind the limitations it may hold. For instance, in our study, hemolysis test cannot be relied upon since lytic enzymes can also lead to clearing zones [29]. However, a concurrent indication of positive results by multiple tests increases the reliability of observations. The drop collapse test is more conclusive comparatively [17]. It relies on the destabilization of liquid droplets by surfactants. In presence of surfactants, the drops spread or even collapse because the force or interfacial tension between the liquid drop, and the hydrophobic surface is reduced. However, in absence of surfactants, the polar water molecules are repelled from the hydrophobic surface and the drops remain stable. The stability of drops is dependent on surfactant concentration and correlates with surface and interfacial tension [17, 29]. 


\subsection{Screening of media for the bio-surfactant production}

Figure 1 represents the three different media used for screening of bio-surfactant production in our study. Maximum reduction of surface tension i.e., 33 dynes/cm was observed in the MSM medium and hence it was used as a production media for further optimization studies. A recent investigation carried out with Acinetobacter junii B6 also reported optimum bio-surfactant production in MSM medium supplemented with 1\% Iranian light crude oil [30].

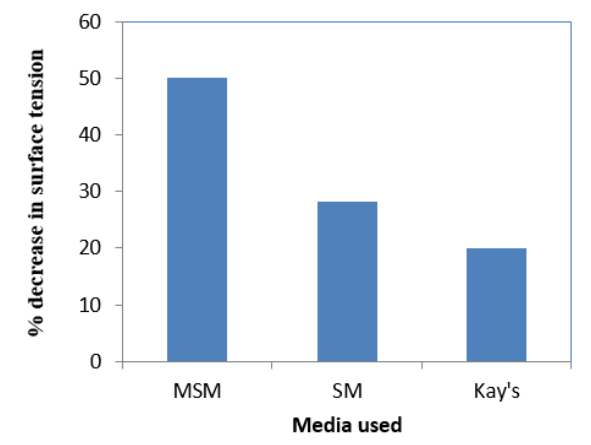

Figure 1 Screening of media for bio-surfactant production

\subsection{Optimization of bio-surfactant production}

Optimization of physicochemical factors is essential for any biological process since they have direct effects on cellular growth and activity. Figures 2-8 represent the optimum parameters required for bio-surfactant production. In the current study, the optimum bio-surfactant production was obtained using $2 \%$ inoculum size of Azorhizobium species (1.0 0.D at 530nm) in MSM medium (pH 8.5) containing 2\% coconut oil and ammonium nitrate with a C: $\mathrm{N}$ ratio of 20:1, and incubation conditions of $30^{\circ} \mathrm{C}$ for $96 \mathrm{~h}$.

A reduction in surface tension by $51 \%$ and emulsification activity of $42 \%$ was observed at pH 8.5 in our study (Figure 2 ). The gradual increase observed in the bio-surfactant production with an increase in the $\mathrm{pH}$ of the culture medium is due to the dependence of enzymatic processes on the same [27]. In a similar study, P. aeruginosa RS29 also required an optimum pH between 8 and 9 for bio-surfactant production [31]. Another study indicated a significant bio-surfactant production by Bacillus brevis in the $\mathrm{pH}$ range of 4-9 [32]. The rhamnolipids produced by P. aeruginosa was found to be tolerant to variations in $\mathrm{pH}$ (6-12) hence making it a good candidate for industrial use [33].

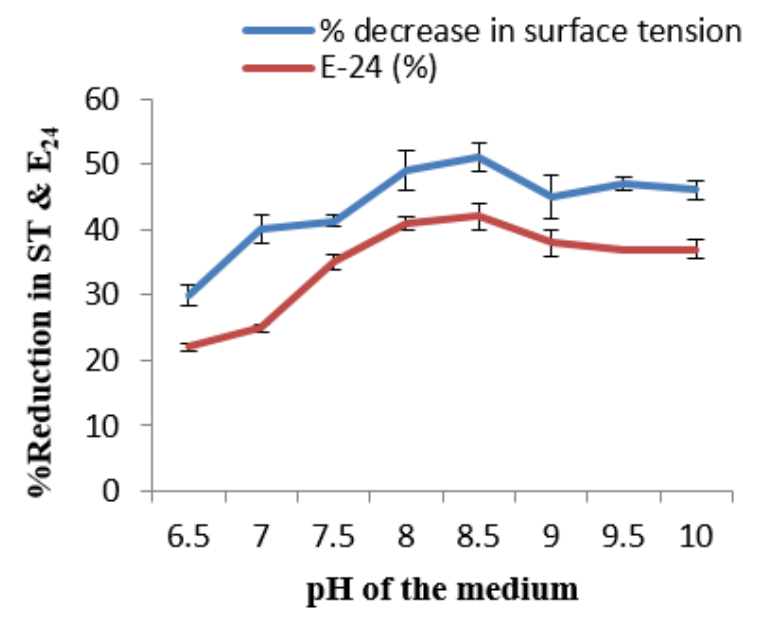

Figure 2 Optimization of pH for production of bio-surfactant by Azorhizobium strain

The optimum temperature for bio-surfactant production was observed to be $30{ }^{\circ} \mathrm{C}$ by Azorhizobium strain in our study. It showed surface tension reduction of the media by $50 \%$ and an emulsification activity of $40 \%$ (Figure 3 ). Similar results were obtained by Padmapriya et al. who reported optimum bio-surfactants production at $40{ }^{\circ} \mathrm{C}$ by Candida species [34]. 
Thermally stable bio-surfactant production was observed by Bacillus brevis in the temperature range of $30-80{ }^{\circ} \mathrm{C}[32]$. Bio-surfactant production has also been reported at low temperatures i. e $20^{\circ} \mathrm{C}$ by Aspergillus species [35].

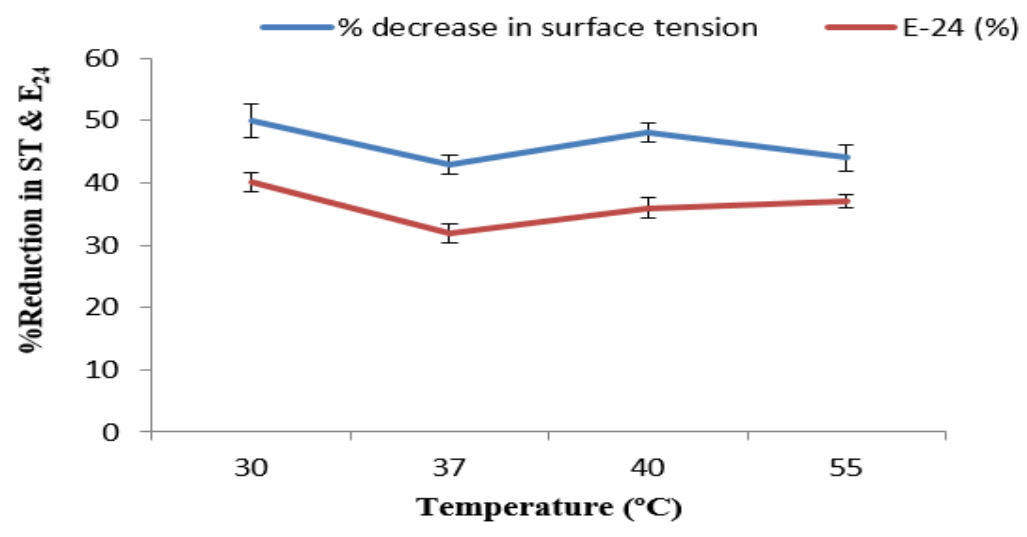

Figure 3 Optimization of temperature for production of bio-surfactant by Azorhizobium strain

The production of bio-surfactant increased considerably after incubation of $96 \mathrm{~h}$ and was found to be stable up to 144 $\mathrm{h}$ in our study (Figure 4). The surface tension reduction and emulsification activity were found to be $49 \%$ and $50.3 \%$ respectively. Initial lag in bio-surfactant production is due to the adaptation of culture to the nutrient media. In certain cases, an increased surface tension is reported in the medium after crossing the optimum temperature range. This is due to the poor bio-surfactant activity observed at critical micelle concentrations. At these concentrations, the surfactant monomers associate into structured aggregates such as micelles, vesicles, and lamellae spontaneously due to weak chemical interactions [36]. Maximum bio-surfactant production has been reported after 7 and 10 days by Brevibacterium species and Bacillus brevis respectively [19, 32].

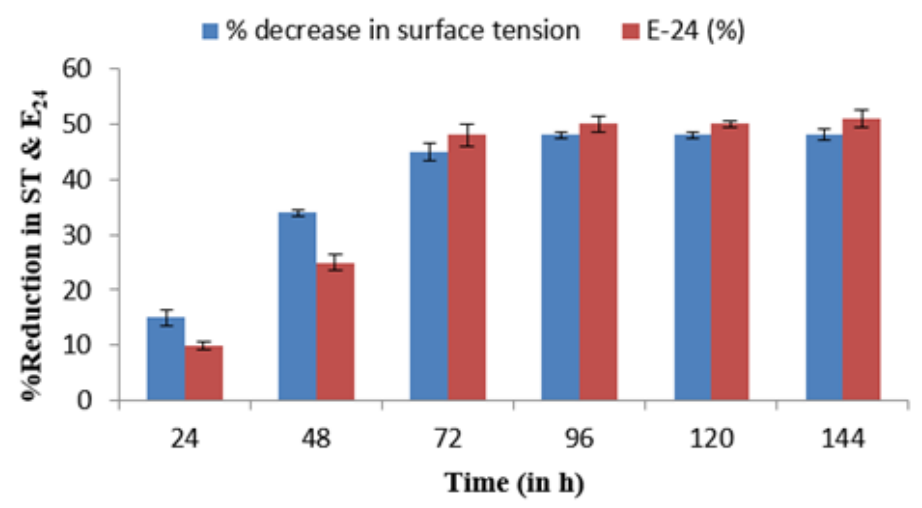

Figure 4 Optimization of the incubation period for production of bio-surfactant by Azorhizobium strain

Among the different carbon and nitrogen sources studied for bio-surfactant production, coconut oil and ammonium nitrate showed maximum surface tension reduction $(55 \%, 53 \%)$ and emulsification activities $(60.2 \%, 58 \%)$ respectively (Figures 5 and 6). A recent study showed that kitchen waste oil can be used as raw material for biosurfactant production by $P$. aeruginosa over other carbon sources. They further reported a higher optical density of 2.33 and lower interfacial tension of $0.57 \mathrm{mN} / \mathrm{m}$. [33]. Another study has previously reported that Pseudomonas species is capable of utilizing different substrates, such as glycerol, mannitol, fructose, glucose, n-paraffins, and vegetable oils to produce rhamnolipid-type bio-surfactants [37]. Other studies have reported ammonium nitrate [38], sodium nitrate $[37,39]$ and corn steep liquor as an optimum nitrogen source for bio-surfactant production by Pseudomonas aeruginosa [37]. A $15 \%$ whey concentration is also shown to positively influence the bio-surfactant production $(8.9 \mathrm{mg} / \mathrm{L})$ and reduce surface tension by about $18.1 \mathrm{mN} / \mathrm{m}[40]$. 


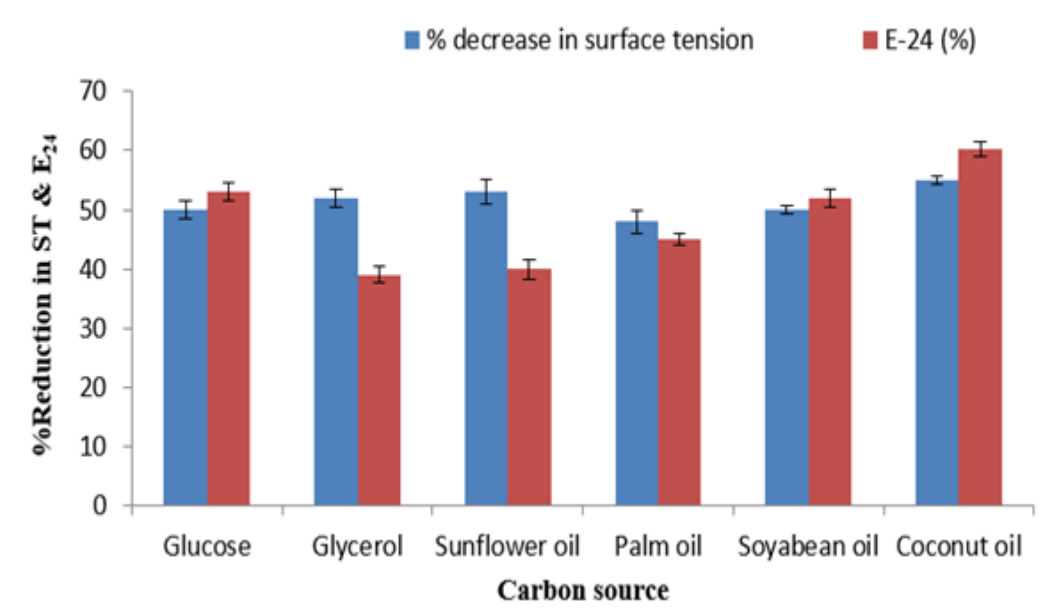

Figure 5 Optimization of carbon source for production of bio-surfactant by Azorhizobium strain

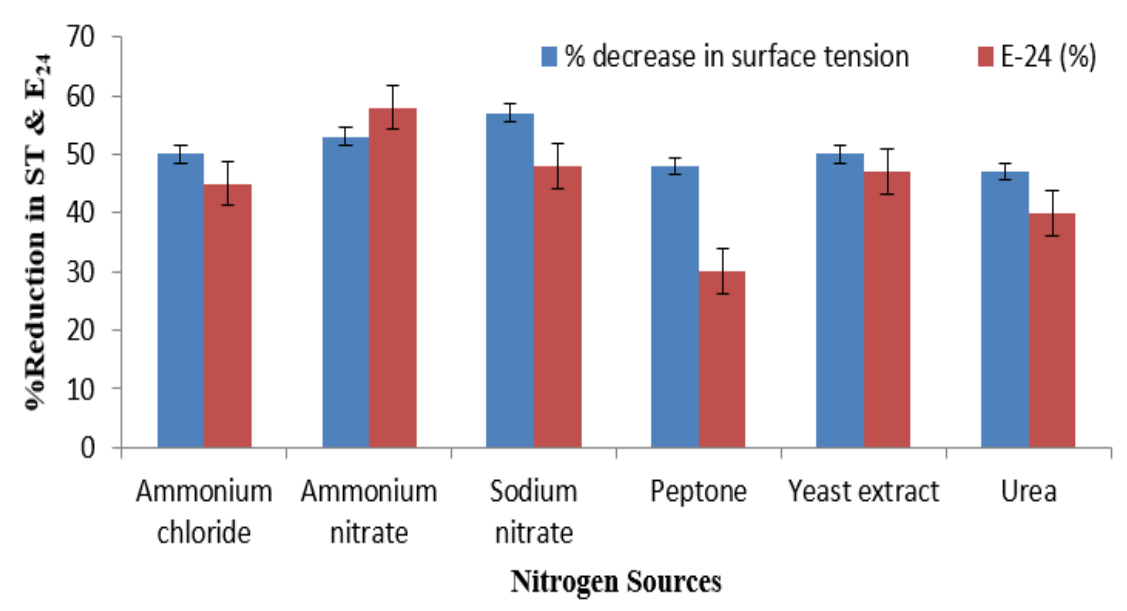

Figure 6 Optimization of nitrogen source for production of bio-surfactant by Azorhizobium strain

In order to obtain high concentrations of bio-surfactant, it is necessary to maintain the carbon to nitrogen ratio. The optimum C: N ratio suitable for bio-surfactant production was found out to be 20:1 in our study (Figure 7). It supported a reduction in surface tension by $55.3 \%$ and showed emulsification activity value of $52.26 \%$. The concentration of nitrogen is reported to be a rate-determining factor during the biosynthesis of rhamnolipid and nitrogen limitation may promote lipid accumulation [41]. In contrast to this, Guerra-Santos et al. showed maximum rhamnolipid production after nitrogen limitation at a $\mathrm{C}$ : $\mathrm{N}$ ratio of $16: 1$ to $18: 1$ and no surfactant production below a C: $\mathrm{N}$ ratio of 11:1 [42]. Abouseoud et al. reported the use of frying oil and sodium nitrate as carbon and nitrogen source respectively at C: $\mathrm{N}$ ratio of 10:1 for effective production of bio-surfactants [43]. 


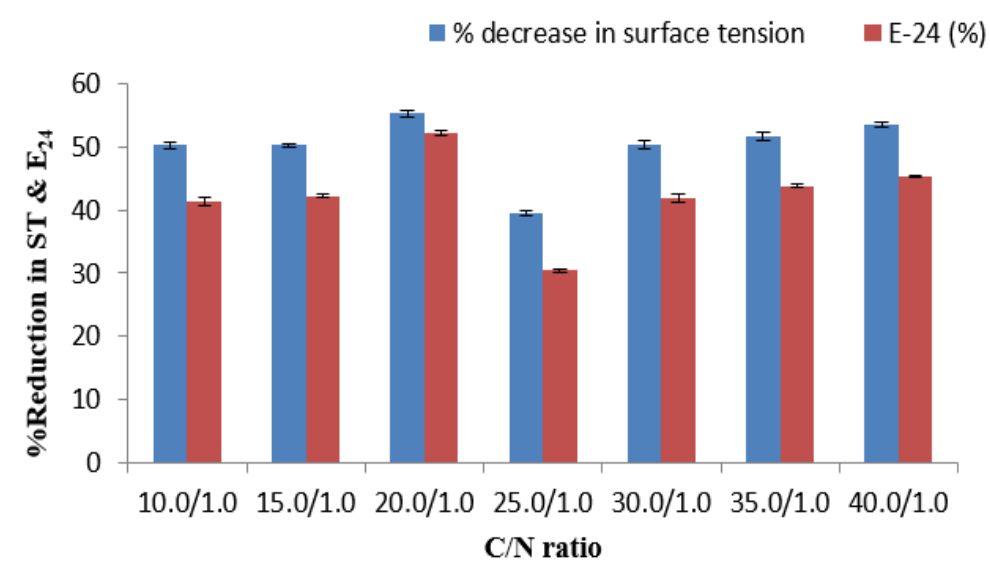

Figure 7 Optimization of carbon: nitrogen ratio for production of bio-surfactant by Azorhizobium strain

The optimum salt concentration was observed to be $1.5 \%$ in our study with $50 \%$ reduction in surface tension and emulsification activity of $36.4 \%$ (Figure 8). Kiran et al. found that the bio-surfactant produced by the marine Brevibacterium aureum MSA13 was stable at high $\mathrm{NaCl}$ (up to 5\%) [19]. A high degree of tolerance was also observed by rhamnolipid producing $P$. aeruginosa against the salinity levels (2-20\% w/v) [33].

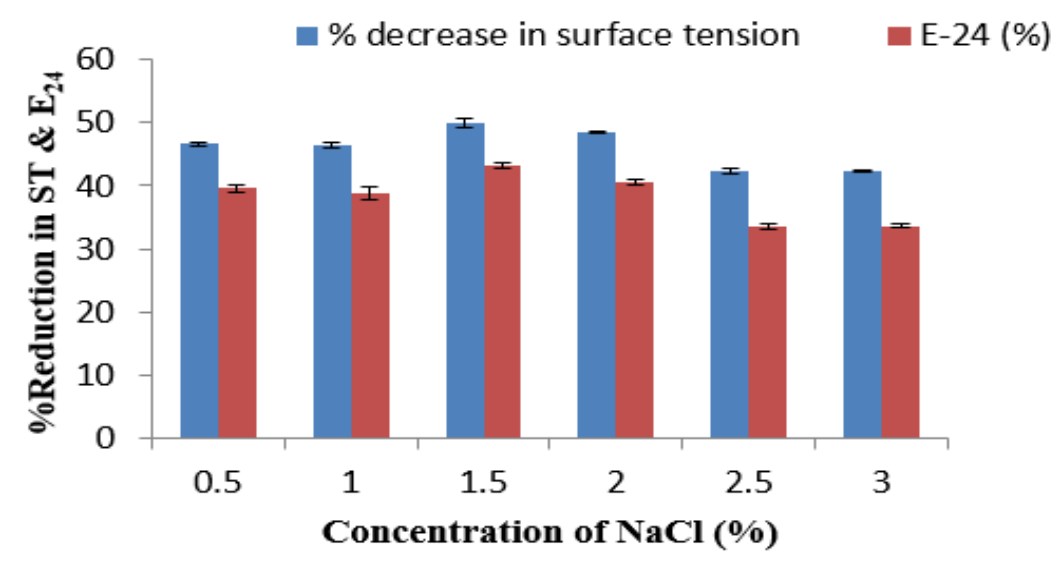

Figure 8 Optimization of $\mathrm{NaCl}$ concentration for production of bio-surfactant by Azorhizobium strain

\subsection{Extraction}

The extraction of bio-surfactant using optimized culture conditions was carried out using acid hydrolysis method and a dry yield of $2.5 \mathrm{~g} / \mathrm{L}$ was obtained. In addition to significant reduction in surface tension (i.e., from $59 \mathrm{mN} / \mathrm{m}$ to 38 $\mathrm{mN} / \mathrm{m}$ ), Azorhizobium species was checked for its ability to emulsify crude oils viz., Diesel, kerosene, sunflower and coconut oil. Our study indicated diesel oil and kerosene to be the best substrates for emulsification activity that was calculated as $60 \%$ and 55\% respectively. A significant emulsification activity was also observed with sunflower oil $(50 \%)$ and coconut oil (48\%). Similar to our study, a 55\% emulsification activity against diesel was observed by the test culture [23]. In another study, the highest emulsification activity of the bio-surfactant for diesel oil (55\%) was produced from isolate B5 using corn oil [44]. Lima et al. reported production of $2.2 \mathrm{~g} / \mathrm{L}$ of rhamnose when ammonium nitrate $(0.56 \%)$ was used as the nitrogen source for P. aeruginosa cultivated in $2.2 \%$ residual soybean oil [45]. Another study reported olive oil as the best carbon source for the production of bio-surfactants by Pseudomonas fluorescence when compared to hexadecane and glucose. In their study, fermentation of olive oil reduced the surface tension of the media to $38 \mathrm{dyne} / \mathrm{cm}$ and showed an emulsification activity of $49 \%$. However, in presence of hexadecane as a carbon source, only $10 \%$ emulsification activity was observed with a significant reduction in surface tension, and no bio-surfactant production was observed in presence of glucose [43]. 


\subsection{Fourier transform infrared spectroscopy analysis}

Figure 9 represents the FTIR spectrum of purified bio-surfactant obtained in our study. In this figure, we can observe the absorbance of $\mathrm{C}-\mathrm{H}$ stretching bond at $3004 \mathrm{~cm}^{-1}$, aliphatic chain- $\mathrm{CH}$ at $2824 \mathrm{~cm}^{-1}, \mathrm{C}=0$ (ketones) at $1710 \mathrm{~cm}-1$, carboxylates at $1420 \mathrm{~cm}^{-1}$ and peptide bond at $1092 \mathrm{~cm}^{-1}$. The absorbance bands at the wavenumbers of 3004-2824 $\mathrm{cm}^{-1}, 1710 \mathrm{~cm}^{-1}, 1200-1500 \mathrm{~cm}^{-1}$ and $900-1200 \mathrm{~cm}^{-1}$ in FTIR spectrum clearly indicate the presence of fatty acids, amides, mixed components, and lipopolysaccharides respectively. The relative position of axial and equatorial (OH) side groups influence the main band frequency positions at $1092 \mathrm{~cm}^{-1}$ and the maximal assigned to ring and side group vibrations can be related to the peptide spectra. The characterization of bio-surfactant revealed its chemical nature to be of lipopolysaccharides type. The molecular composition of the bio-surfactant determined by FTIR and nuclear magnetic resonance confirmed the presence of carbohydrates, lipids and proteins, defining this molecule as a glycolipopeptide [40].

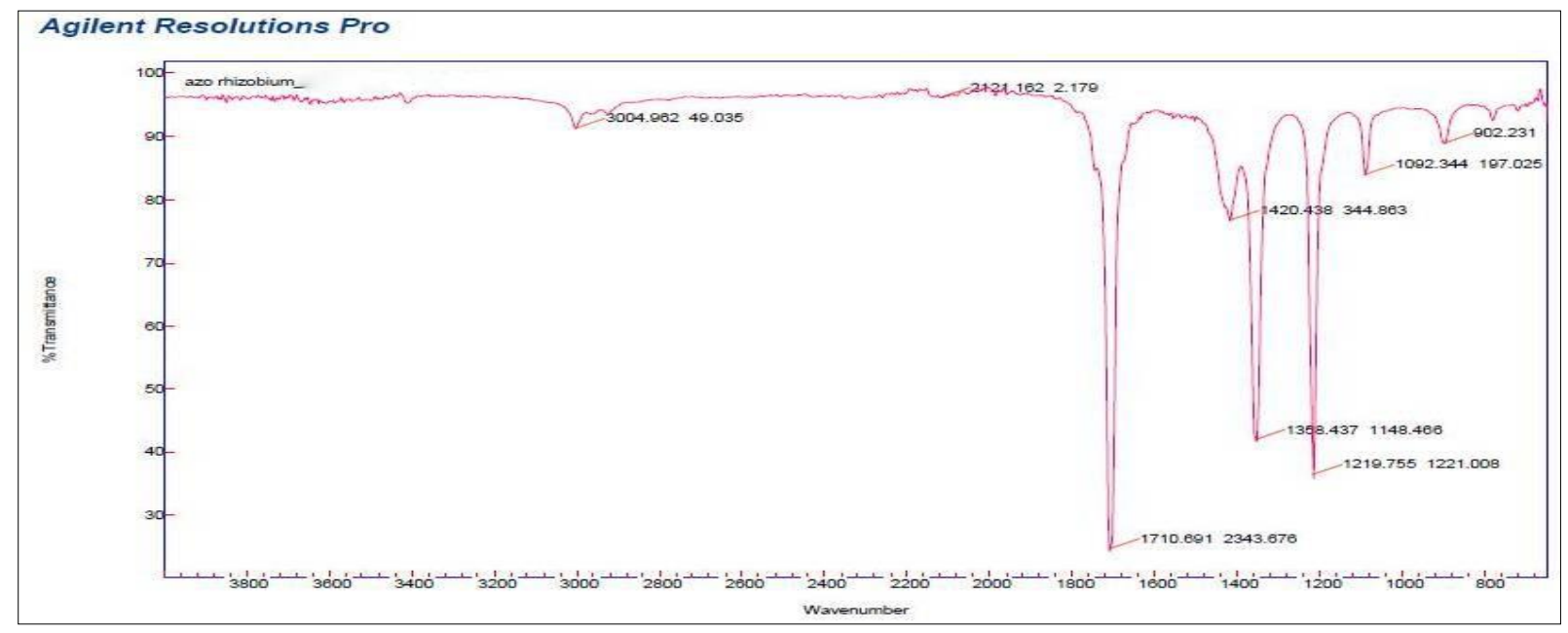

Figure 9 FTIR spectrum of purified biosurfactant

\section{Conclusion}

A large number of studies carried out for use of microbial bio-surfactants highlight its extensive potential in industries. In this regard, our study provides challenging outputs with high yielding ( $2.5 \mathrm{~g} / \mathrm{L}$ ) strain of Azorhizobium species. With further optimization studies and molecular insights, it can help in overcoming problems associated with oil recovery and bioremediation of oil-contaminated sites.

\section{Compliance with ethical standards}

\section{Disclosure of conflict of interest}

All authors declare that they have no conflict of interest.

\section{References}

[1] Samanta SK, Singh OV and Jain RK. (2002). Polycyclic aromatic hydrocarbons: Environmental pollution and bioremediation. Trends in Biotechnology, 20(6), 243-248.

[2] Wong JWC, Fang M, Zhao Z and Xing B. (2004). Effect of surfactants on solubilization and degradation of phenanthrene under thermophilic conditions. Journal of Environmental Quality, 33(6), 2015-2025.

[3] Lu JR, Zhao XB and Yaseen M. (2007). Biomimetic amphiphiles: biosurfactants. Current Opinion in Colloid and Interface Science, 12(2), 60-67.

[4] Ward O, Singh A and Van Hamme J. (2003). Accelerated biodegradation of petroleum hydrocarbon waste. Journal of Industrial Microbiology and Biotechnology, 30(5), 260- 270. 
[5] Maier RM and Zhang Y. (1997). Measurement of biosurfactants enhanced solubilization and biodegradation of hydrocarbons, bioremediation protocols. Humana Press, New Jersey, 59-66.

[6] Gibson DT and Subramanian V. (1984). Microbial degradation of organic compounds. New York, USA, Marcel Dekker, 181-252.

[7] Whang LM, Liu PW, Ma CC and Cheng SS. (2008). Application of biosurfactant, rhamnolipid, and surfactin, for enhanced biodegradation of diesel-contaminated water and soil. Journal of Hazardous Materials, 151(1), 155163.

[8] Nguyen TT, Youssef NH, McInerney MJ and Sabatini DA. (2008). Rhamnolipid biosurfactant mixtures for environmental remediation. Water Research, 42(6-7), 1735-1743.

[9] Misun Chi, Seyom T, Eaton KM, Zalenskya I, Hagver R and Gross R. (2005). Sophorolipids, microbial glycolipids with anti-human immunodefficiency virus and sperm-immobilising activities. Antimicrobial Agents and Chemotherapy, 49(10), 4093-4100.

[10] Desai JD and Banat IM. (1997). Microbial production of surfactants and their commercial potential. Microbiological Molecular Reviews, 61(1), 47-64.

[11] Kosaric N. (1992). Biosurfactants in industry. Pure and Applied Chemistry, 64(11), 1731-1737.

[12] Kapadia SG and Yagnik BN. (2013). Current Trend and Potential for Microbial Biosurfactants. Asian Journal of Experimental and Biological Sciences, 4(1), 1-8.

[13] Wilde P, Mackie A, Husband F, Gunning P and Morris V. (2004). Proteins and emulsifiers at liquid interfaces. Advances in Colloid and Interface Science, 108-109, 63-71.

[14] Goswami P and Singh HD. (1991). Different modes of hydrocarbon uptake by two different Pseudomonas spp. Biotechnology and Bioengineering, 37(1), 1-11.

[15] Karanth NGK, Deo PG and Veenanadig NK. (1999). Microbial production of biosurfactants and their importance. Current Science, 77(1), 116-123.

[16] Cameotra SS and Makkar RS. (2010). Biosurfactant enhanced bioremediation of hydrophobic pollutants. Pure and Applied Chemistry, 82(1), 97-116.

[17] Plaza GA, Zjawiony I and Banat IM. (2006). Use of different methods for detection of thermophilic biosurfactantproducing bacteria from hydrocarbon-contaminated abioremediated soils. Journal of Petroleum Science and Technology, 50(1), 71-77.

[18] Kronemberger FDA, Santa Anna LMM, Fernandes ACLB, Menezes RRD, Borges CP and Freire DMG. (2008). Oxygen-controlled biosurfactant production in a bench-scale bioreactor. Applied Biochemistry and Biotechnology, 147(1-3), 33-45.

[19] Kiran GS, Thomas TA, Selvin JS and Lipton AP. (2010). Optimization and characterization of a new lipopeptide biosurfactant produced by marine Brevibacterium aureum MSA13 in solid state culture. Bioresource Technology, 101(7), 2389-2396.

[20] Anandaraj B and Thivakara P. (2010). Isolation and production of biosurfactant producing organism from oil spilled soil. Journal of. Bioscience and Technology, 1(3), 120-126.

[21] Youssef NH, Duncan KE, Nagle DP, Savage KN, Knapp RM and McInerneya MJ. (2004). Comparison of methods to detect biosurfactant production by diverse microorganisms. Journal of Microbiological Methods, 56(3), 339-347.

[22] Buchanan RE and Gibbons NE. (1974). Bergey's Manual of Determinative Bacteriology, Eighth Edition, The Williams and Wilkins Company/ Baltimore, 217-242.

[23] Abouseoud M, Maachi R, Amrane A, Boudergua S and Nabi A. (2008). Evaluation of different carbon and nitrogen sources in production of biosurfactant by Pseudomonas fluorescens. Desalination, 223(1-3), 143-151.

[24] Zhang Y and Miller RM. (1992). Enhanced octadecane dispersion and biodegradation by a Pseudomonas rhamnolipid surfactant (biosurfactant). Applied and Environmental Microbiology, 58(10), 3276-3282.

[25] Samadi N, Abadian N, Akhavan A, Fazeli MR, Tahzibi A and Jamalifar H. (2007). Biosurfactant production by the strain isolation from contamination soil. Journal of Biological Sciences, 7(7), 1266-1269.

[26] Hamzah A, Sabturani N and Radiman S. (2013). Screening and Optimization of Biosurfactant Production by the Hydrocarbon-degrading Bacteria. Sains Malaysiana, 42(5), 615-623. 
[27] Mata-Sandoval JC, Karns J and Torronts A. (2000). Effect of nutritional and environmental conditions on the production and composition of rhamnolipds by Pseudomonas aeruginosa UG2. Microbiological Research, 155(4), 249-56.

[28] Govindammal M and Parthasarathi R. (2013). Production and Characterization of Bio Surfactant Using Renewable Substrates by Pseudomonas fluorescence Isolated from Mangrove Ecosystem. Journal of Applicable Chemistry, 2(1), 55-62.

[29] Jain DK, Collins-Thompson DL, Lee H and Trevors T. (1991). A drop collapsing test for screening surfactantproducing microorganisms. Journal of Microbiological Methods, 13(4), 271-279.

[30] Mandana O, Gholamreza D, Mojtaba S, Ibrahim MB, Mostafa P and Hamid Forootanfar. (2017). Isolation, characterization, and optimization of biosurfactant production by an oil-degrading Acinetobacter junii B6 isolated from an Iranian oil excavation site. Biocatalysis and Agricultural Biotechnology, 12, 1-9.

[31] Saikia RR, Deka S, Deka M and Banat IM. (2012). Isolation of biosurfactant producing Pseudomonas aeruginosa RS29 from oil-contaminated soil and evaluation of different nitrogen sources in biosurfactant production Annals of Microbiology, 62(2), 753-763.

[32] Mouafi FE, Abo Elsoud MM and Moharam ME. (2016). Optimization of biosurfactant production by Bacillus brevis using response surface methodology. Biotechnology Reports, 9, 31-37.

[33] Chen C, Sun N, Li D, Long S, Tang X, Xiao G and Wang L. (2018). Optimization and characterization of biosurfactant production from kitchen waste oil using Pseudomonas aeruginosa. Environmental Science and Pollution Research, 1-10.

[34] Padmapriya B, Suganthi S and Anishya RS. (2013). Screening, optimization and production of biosurfactants by Candida species isolated from oil polluted sites. Journal of Agricultural and Environmental Sciences, 13(2), 227233.

[35] Kiran GS, Hema TA, Gandhimathi R, Selvin J, Thomas TA, Rajeetha RT and Natarajaseenivasan K. (2009). Optimization and production of a biosurfactant from the sponge-associated marine fungus Aspergillus ustus MSF3. Colloids and Surfaces, B: Biointerfaces, 73, 250-256.

[36] Soberón CG and Maier RM. (2011) Biosurfactants: A General Overview. In: Soberón-Chávez G. (eds) Biosurfactants. Microbiology Monographs, vol 20. Springer, Berlin, Heidelberg.

[37] Senthil BS and Jayalakshmi S. (2013). Glycolipid biosurfactant production using low cost medium from marine bacterium Pseudomonas aeruginosa of Mudasalodai coast. International Journal of Green Chemistry and Bioprocess, 3(3), 33-37.

[38] Healy MG, Devine CM and Murphy R. (1996). Microbial production of biosurfactants. Resources, Conservation and Recycling, 18(1-4), 41-57.

[39] Peng F, Wang Y, Sun F, Liu Z, Lai Q and Shao Z. (2008). A novel lipopeptide produced by a Pacific Ocean deep-sea bacterium, Rhodococcus sp TW53. Journal of Applied Microbiology, 105(3), 698-705.

[40] Ellen CSV, Pamela ODA, José MD and Ricardo PDO. (2018). Optimization of biosurfactant and bacteriocin-like inhibitory substance (BLIS) production by Lactococcus lactis CECT-4434 from agro-industrial waste. Biochemical Engineering Journal, 133, 168-178.

[41] Mercade ME and Manresa MA. (1994). The use of agroindustrial by products for biosurfactant production. Journal of the American Oil Chemists Society, 71(1), 61-64.

[42] Guerra SL, Kappeli HO and Fiechter A. (1984). Pseudomonas aeruginosa biosurfactant production in continuous culture with glucose as carbon source. Applied and Environmental Microbiology, 48(2), 301-305.

[43] Abouseoud M, Maachi R and Amrane A. (2007). Biosurfactant Production from olive oil by Pseudomonas fluorescens. In: Méndez-Vilas (Ed.) Communicating Current Research and Educational Topics and Trends in Applied Microbiology, 340-347.

[44] Sifour M, Al-Jilawai M and Aziz G. (2007). Emulsification properties of biosurfactants produced from Pseudomonas aeruginosa RB28. Pakistan Journal of Biological Sciences, 10(8), 1331-1335.

[45] Lima CJ, Ribeiro EJ, Sérvulo EF, Resende MM and Cardoso VL. (2009). Biosurfactant production by Pseudomonas aeruginosa grown in residual soybean oil. Applied Biochemistry and Biotechnology, 152(1), 156-68. 
Pendse et al. / GSC Biological and Pharmaceutical Sciences 2018, 03(03), 035-046

\section{How to cite this article}

Pendse A, Mhatre R and Aruna K. (2018). Optimization of bio-surfactant production by Azo-rhizobium strain isolated from oil-contaminated soil. GSC Biological and Pharmaceutical Sciences, 3(3), 35-46. 